\title{
A bibliometric analysis of tropical mangrove forest land use change from 2010 to 2020
}

\author{
Sheriza Mohd Razali ${ }^{1}$ (D) Maizatul Azwa Radzi ${ }^{1} \cdot$ Arnaldo Marin $^{2} \cdot$ Zaiton Samdin $^{1}$
}

Received: 28 October 2020 / Accepted: 27 October 2021 / Published online: 14 November 2021

(c) The Author(s), under exclusive licence to Springer Nature B.V. 2021

\begin{abstract}
Mangrove land use changes of varied intensities have long been a problem in tropical mangrove forests. This has resulted in various degrees of mangrove land use modification, which catch many interests in the region for research. The research provided here is a bibliometric analysis of scholarly articles published around the world in various publication document types on changes in land use of tropical mangrove forests based on remote sensing and Geographical Information System (GIS). Scientific data analysis was undertaken by using bibliometric approaches on 6,574 papers extracted from the Scopus databases between 2010 and 2020. The findings revealed that the number of publications continuously climbed from under 400 to an average of 50-60 per year till 2019. The data showed that the mangrove forest modifications study gained traction when the highest number of citations, 9,236 in 2015, were observed. We can also notice that the overall number of citations fluctuated a lot during the first five years (2010-2015) but increased from 2013 to 2015. The findings demonstrate how remote sensing satellites have aided vegetation and land study in recent years. The findings also revealed that the analysis tools of Land Use Change, Vegetation Index, Mangrove, Tropical Country, Remote Sensing, and Tropical contributed to scientific knowledge of current issues of mangrove land use change in the tropical region. The authors' keywords, Remote Sensing in particular, supplied roughly $43 \%$, Normalized Difference Vegetation Index (13\%), Vegetation Index (9\%), and other keywords contributed less than 7\%. The growth pattern of the keywords "MODIS" and "Landsat" implies that both will stay important over the next five years, according to an analysis of the type of satellite used in land use assessment. Meanwhile, papers pertaining to policy on land use change, food security, and forest resources were evaluated in order to highlight policy and academic research findings on the topics. The application of the Normalized Difference Vegetation Index, which is a very relevant tool that can be used in monitoring land use changes and assessing vegetation status because it is a desirable technique in measuring plant health and vigour, can help fill the research gaps presented in this study. This review can help with the development of better mangrove land use change approaches in tropical mangroves and around the world using satellite remote sensing and GIS.
\end{abstract}

Keywords Mangrove $\cdot$ Land use change $\cdot$ MODIS $\cdot$ Malaysia

Sheriza Mohd Razali

sheriza@upm.edu.my

Extended author information available on the last page of the article 


\section{Introduction}

Realizing the importance of land and oceanic region to human life has motivated continual studies and explorations of this field. One of the most powerful tools to explore the land is remote sensing techniques. Both remote sensing and GIS have become indispensable, particularly in the tropical region for forest monitoring, irrigation, land use, and others. For example, the application of remote sensing and GIS is common in monitoring mangroves in tropical region. Mangroves, as we know, provide a wide variety of ecosystem services, such as protecting the coast from erosion and home to various organisms that are beneficial for humans. Remote sensing helps to monitor recent issues on mangrove degradation. The decline of mangroves these days is alarming, and it is crucial to revise the status of the mangrove forests.

Over the last decade, there is a soaring interest in the application of remote sensing and GIS in tropical mangrove studies. The outstanding role of remote sensing in provisioning information on Earth and water surfaces has drawn the attention of researchers all over the world. There are also various new techniques in GIS and their broad application in remote sensing reported recently. For example, Mao et al., (2013) developed a new approach to estimate epsilon for atmospheric correction of satellite image data that can be applied for the coastal and oceanic region. Zabolotskikh et al., (2013), on the other hand, developed a novel algorithm for the accurate estimation of sea surface wind speed and applied it to satellite passive microwave sensing. Most recently, the application of remote sensing is reported by Cardoso-Fernandes et al., (2019) to observe and map lithium (Li) bearing pegmatites in the Fregeneda-Almendra region. A canopy height model was developed using a machine learning algorithm approach coupled with the application of Landsat satellite sensors for vegetation in the Darwin area, Northern Australia (Staben et al., 2018). Meanwhile, a recent study by Yu et al., (2019) tested a new methodology called backdating and an object-based method for accurate land cover classification and change analysis. From the viewpoint of a researcher, a comprehensive review of this subject can be a valuable reference for future scientists in mangrove land-use change that integrates remote sensing and GIS techniques.

Tropical countries are regions located along the equator of the Earth that can be divided into several continents, including North America, South America, and Southeast Asia. Most tropical countries experience a dry and wet season throughout the year. The abundance and diversity of tropical regions are well documented, as evidenced by the numerous studies that have been undertaken. These studies reflect the objectives of RAMSAR. For example, Oostdijk et al., (2018) applied remote sensing using high-resolution satellite image to determine improvements in mangrove forests under different hydrological condition. Pham et al., (2019) used remote sensing to evaluate the growth of mangrove forests in Can Gio, Vietnam. Cissel et al., (2018) monitored the changes in the mangrove forest in Campeche, Mexico using satellite data from Landsat. Earlier, Jia et al., (2018) discovered the decline and growth of mangrove forests that provided the first dataset of mangrove forests for more than 40 years in China using remote sensing analysis. There is also a study on a 15-year time series of four vegetation indices that were used to assess the phenology of mangrove forest in Southeast Mexico (Pastor-Guzman et al., 2018).

Malaysia became a party to the Convention on Biological Diversity in 1992 and the National Biodiversity Committee that was set up in 1994 to protect and manage international biological resource and to ensure the fair and equitable sharing of biological resources and technology. Tanjung Piai is one of the mangrove forests in Malaysia 
identified as one of the RAMSAR sites that is considered as "Wetland of International Importance". Other countries such as Thailand, Vietnam, Laos, and Indonesia also participate in the RAMSAR party, and they have at least one mangrove identified that was adopted to this convention. Generally, policy and decision-makers base their development decisions upon simple monetary calculations, i.e. pros and cons of the proposals presented before them; however, the importance of wetlands for the environment and human societies is traditionally underrated in these calculations because of the difficulty of assigning dollar values to the wetland ecosystem's values and benefits, goods and services (Ramsar, 2016).

Bibliometric analysis is an effective research tool widely used in various fields of scientific investigation. Recently, Duan et al., (2020) conducted a bibliometric analysis to evaluate the application of remote sensing in monitoring protected areas. Wang et al., (2019a, $2019 \mathrm{~b}$ ) provided new insights into research trends of remote sensing in crop growth monitoring in China over the past 20 years through bibliometric analysis. Elsewhere, bibliometric analysis is also applied in physical activity and ageing studies (Muller et al., 2016). Most importantly, it is a method that can provide a detailed overview of global trends for a given research area. Notably, a bibliometric analysis by Huang and Lu, (2017) on the history and trend of urban heat island research from 1991 to 2015. In summary, the bibliometric technique is able to draw out information on current topics, the most advanced and knowledge gaps in a particular field of study. In remote sensing, bibliometric analysis helps reveal and determine the trends in research publication and its application. For example, a bibliometric analysis was conducted in the field of engineering to assess the current development of Industry 4.0 (Muhuri et al., 2019). In a case study in China, bibliometric analysis was used to monitor the research trends in support vector machines, one of the classification techniques for remote sensing (Yu et al., 2019). Therefore, bibliometric analysis has been effective in identifying research trends in various scientific fields.

It is essential to identify the patterns of publication in the studies of mangrove land use change using remotes sensing/GIS. This is because there have been limited studies and updated reviews on land use change, particularly on remote sensing in the tropical region, which deserve to be highlighted. Accordingly, the database of the Academia provides the source for bibliometric analysis on drought monitoring study and prediction in Africa (Adisa et al., 2020). Meanwhile, numerous reviews are conducted on mangrove ecosystems (ResearchGate.net), recent status on mangrove in Brazil (mdpi.com) (Diniz et al., 2019), and carbon stock assessment of mangrove using remote sensing (ReseachGate.net) (Bindu et al., 2020). However, the reviews on mangrove land use change in tropical countries are limited with the most recent ones by Kuenzer et al. (2011) and Wang et al., (2019a, 2019b) on the evaluation of mangrove using remote sensing techniques.

The selection of keywords is based on the high usage of satellites, such as Landsat in land use studies, which has witnessed a rapid increase in land use change related to mangrove forests. There is also MODIS, a highly dependent land product for vegetation status, which offers a vast utilization in the tropical region. The present study found that using the uppermost research topic in mangrove land use change studies generates one of the informative articles that can be used as a reference for future studies in remote sensing application, particularly in assessing land use change in tropical mangroves. Furthermore, such research conducted in that locality can provide valuable input for human intervention in the events of natural disasters such as tsunami and flooding. It may assist policymakers and land managers in constructing new methods for managing their forest and land for food security (Rochdane et al., 2014). Moreover, research on the application of remote sensing is ongoing in search of a better classification method for 
forested land to assist policymaker in managing forested land (Alon et al., 2020; Panuju et al., 2020), specifically in mangrove (Amoakoh et al., 2021).

Therefore, the main objective of this study was to evaluate the scientific knowledge on changes in land use of tropical mangrove forests that are based on the use of remote sensing. Specifically, the study investigated the patterns in the occurrence of land use change through the evolution of publications. To achieve this, a bibliometric analysis of mangrove land use change that employs remote sensing/GIS techniques was performed from 2010-2020. Studies that are published throughout this period have demonstrated the extensive application of the method to monitor land use in tropical mangrove along with the discovery of other novel approaches. The missing link is the connection between the challenge of developing techniques and managing a rapid change of environment. Based on the critical review of the methodology, it is hoped that the outcomes could provide valuable insight into the policy impact on the studied issue. Most importantly, the researchers could utilize the information as an input in establishing the groundwork for presenting solutions to national crises to the government and policymakers.

\section{Materials and methods}

\subsection{Materials}

In this study, scientific documents on mangrove land use change using remote sensing were retrieved from Scopus, which is most commonly used as the core collection database for bibliographic analysis research with more than 15,000 peer-reviewed literature. In the Scopus database, users can refine search results by the types of documents. Keywords are included in the title, abstract, and keywords of the quest. The results were refined according to tropical countries retrieved from Hobo Traveler.com (https://www.hobotraveler.com/ tropical/list-ofotropicalcountries.php); the searching period was limited to the year between 2010 and 2020. Various keywords were entered on the search for remote sensing-based, land use change of mangroves in tropical countries. For example, "land use change" AND "vegetation index" AND "mangrove" AND "tropical country". Another combination was also attempted, for example, "vegetation index", OR "remote sensing" AND "mangrove" AND "land use change". The words "tropical", "tropical country", and "tropical climate" were used in every query. In total, 7,356 documents were retrieved from the search. Data were manually sorted to omit duplicates of documents. As a result, a total of 6,574 records were recovered. Table 1 summarizes the characteristics of the retrieved documents, based on document type, e.g. articles, book chapters, letter, etc.

The retrieved documents comprised of studies published as conference paper, review and book chapters that are influential materials in mangrove land use change in remote sensing topic. Other materials of little influence on the topic are documents providing commentary, editorials and opinion such as editorial materials. The selection of an enormous type of document category enables policy and relevant organization to access the information in a short time. The study found that such materials, which can be in the form of letter-rapid or short communication available in open access, are highly relevant and therefore included in document analyses for this study. The 10 top-keywords that emerged from this study were subjected to further analysis. 
Table 1 Types of documents considered in mangrove land use change using remote sensing in tropical countries (2010-2020)

\begin{tabular}{ll}
\hline Document Type & $\begin{array}{l}\text { Number of } \\
\text { Documents }\end{array}$ \\
\hline Articles & 4,796 \\
Conference papers & 1,618 \\
Review & 76 \\
Book chapter & 69 \\
Note & 4 \\
Short survey & 4 \\
Data paper & 3 \\
Editorial material & 3 \\
Letter & 1 \\
Total & 6,574 \\
\hline
\end{tabular}

\section{Results}

\subsection{Trends in scientific publication of mangrove land use change using remote sensing in tropical countries}

Figure 1 depicts the annual distribution of published articles in mangrove land use change using remote sensing between 2010 and 2020 . The research efforts began to gain traction in 2010. From under 400 publications, the number steadily increased for an average of 50-60 publication per year until 2019. However, it fell slightly in 2020 to a total of 738 publications. Overall, a total of 64,481 citations from the Scopus database were collected for the mangrove study.

In terms of the citation, a maximum number of citations was recorded in 2015 , with a total of 9,236. (Fig. 2) We can see from the figure that the total citations fluctuated significantly for the first five years (2010-2015) but showed an increment from 2013 to

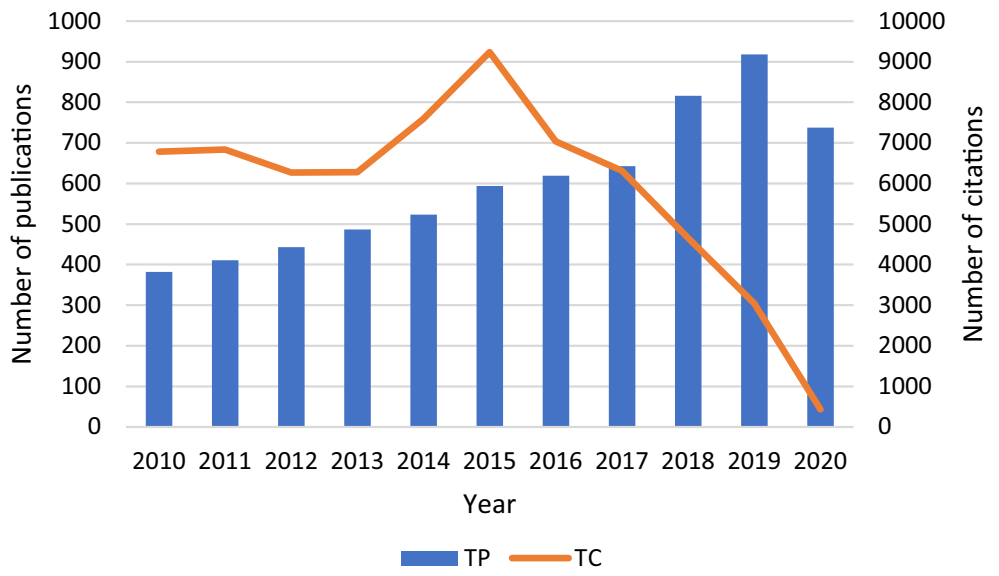

Fig. 1 Number of publications and citations for mangrove land use change using remote sensing in tropical countries (2010-2020) 


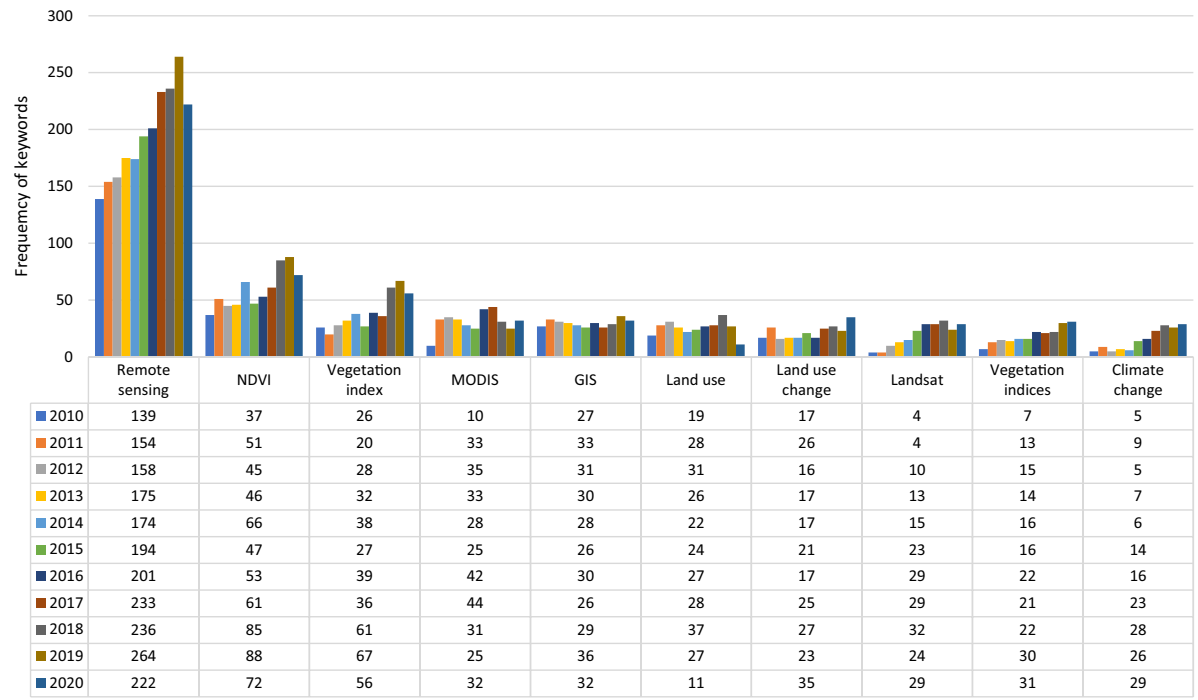

Fig. 2 Annual distribution of keywords in mangrove land use change using remote sensing studies in tropical countries (2010-2020)

2015. The study found that the number of citations fell from 9,236 to 432 in the next five years (2016-2020).

\subsection{Publication citation analysis}

The study by Giri et al. (2010), which has more than 1,000 citations, has the highest number of citations with 1,137 . The paper deals with the monitoring of mangrove distribution using satellite data, and the results concluded that the highest distribution of mangroves is in Asia, which accounts for $42 \%$ of the world's mangrove forests. The second paper with the highest number of citations is Jiyuan et al. (2014), with total citations of 591, on the evaluation of land use changes, causes and trends in China. A moderate citation with a total count of 241 citations was reported by Rudorff et al. (2010) that was published in the journal Remote Sensing of Issue 4, page 1057-1076.

Publications on remote sensing research in tropical countries have one of the lowest citation rates. There are 823 articles with just one citation. In 2020, 112 of the 823 papers were published as articles. The lack of attention from researchers and recent publication may have contributed to the reason for these papers having only one citation. The publication by Olorunfemi et al. (2020), which deals on the vulnerability of flooding and soil erosion in Southwestern Nigeria, is one of the papers with one citation. It also explains the considerable attention on remote sensing-based research in tropical countries during the first five years of the study period relative to recent years, and the research was based on mangrove land use change monitoring. 


\subsection{Keyword's and publication analysis}

Table 2 reveals the top 10 keywords most used by researchers in mangrove land use change using remote sensing/GIS. These keywords were extracted from the title or abstract of the 6,527 analysed data, and a total of 33,130 keywords were extracted. Specifically, 5,002 keywords emerged from the 6,574 publications.

\section{Discussion}

\subsection{Top 10 keyword's analysis}

Floods, landslides, and tsunamis are typical natural disasters that occur in tropical regions. Such disasters have had a great deal of impact on the countries involved, especially on the land cover or land use. Because more disasters have happened in the region, more research has been conducted in places where they are more likely to occur, as seen by the increase in the number of keywords for "climate change". A study in Little Andaman Island, India, was carried out to track land use changes before and after a tsunami had occurred (Shankar et al., 2013), which demonstrated the use of the "climate change" keyword. Since the occurrence of the tsunami in Japan in 2011, more studies are published such as Sharma et al., (2011) who tracked land use changes caused by heavy flooding that occurred in 2005 in Gujarat, India, affecting three districts. Later, Liou et al., (2012) also use MODIS information to evaluate the rice field and yield losses in Fukushima and Miyagi after a tsunami had occurred in 2011 that was triggered by the Great East Japan Earthquake. Thus, it can be inferred that researchers have gained considerable interests in climate change studies as demonstrated by "climate change" and "remote sensing" keywords in certain subjects as a result of the occurrence of incidents and disaster in a region.

For the past 10 years, remote sensing has been a major prospect for monitoring land use change based on the "land-use" and "land-use change" keywords. Most of the papers published in 2010-2020 focused on land use or land cover change, which are based on the title of the research since many mangrove forest areas were converted to agricultural land for food security purposes. Jiyuan et al., (2014), for example, published work on tracking land use changes in China to update its Land-Use/Cover Datasets (CLUDs), which received 591

Table 2 Analysis of the top 10 keywords of mangrove land use change using remote sensing in tropical countries $(2010-2020)$

\begin{tabular}{llcl}
\hline No & Keywords & Frequency & Percentage (\%) \\
\hline 1 & Remote sensing & 2,150 & 43 \\
2 & NDVI & 649 & 13 \\
3 & Vegetation index & 430 & 9 \\
4 & MODIS & 337 & 7 \\
5 & GIS & 328 & 6 \\
6 & Land use & 280 & 6 \\
7 & Land use change & 241 & 5 \\
8 & Landsat & 212 & 4 \\
9 & Vegetation indices & 207 & 4 \\
10 & Climate change & 168 & 3 \\
Total & & 5,002 & \\
\hline
\end{tabular}


citations. The research has identified the conversion from forests to cities as a method to accommodate migrating workers from the villages and suburbs. A larger area for urbanization is required, as evidenced by the massive malls that have sprung up in recent years in major cities. As a result, the government is mapping the demands of departmental and private sectors for land use planning for future urbanization projects. These require updated land use maps, and hence, more studies anticipate new techniques for rapid and accurate maps. Meanwhile, the urbanization in Shanghai, China, during the transformative economy (1979-2009) occurs at a rapid rate (Yin et al., 2011), and its publication was one of the earlier contributing researches to the "land-use" and "land use change" keywords.

In contrast, the use of "land use" as a keyword has declined. Its rank has dropped from fifth in 2010 to $15^{\text {th }}$ in 2020 . Therefore, the present study uses the keyword "land use changes" instead of "land use" for clarity purposes. Also, since many land use changes have happened because of the urbanization across the globes, research has mostly employed the available satellite in evaluating land use change before and after the urban development. Accordingly, numerous studies have utilized remote sensing to investigate the driving causes of land use change (Qasim et al., 2013); update land use maps using different classification methods due to the rapid land use change (Deilmai et al., 2014); mapping agricultural areas to aid governmental planning on important crop area status (Razali et al., 2014), and land use change effects on coastal wetlands (Razali et al., 2014).

\subsection{Normalized difference vegetation index (NDVI)}

The Normalized Difference Vegetation Measure, or NDVI, is a vegetation index that can discern areas of vegetation and their state in general. Many papers on NDVI evaluation have been published in parallel in remote sensing journals. The terms "NDVI" and "vegetation indices" refer to quantitative vegetation analysis used in remote sensing studies. NDVI was, in fact, one of the hottest subjects among scholars over the 11-years. Before 2010, NDVI was used as a precursor for vegetation research, but it was shown to be very efficient for global use. Therefore, the continuous use in studies makes it the second most often used keyword. Besides, the NDVI is also used to classify diverse types of vegetation. For example, NDVI has been proven to detect senescence in a wheat crop cultivated in Mexico (Lopes \& Reynolds, 2012). In India, the use of NDVI is extensive owing to the country's high population, which necessitates the comprehensive use of remote sensing indices in order to protect its natural resources and green land for future generations. The NDVI is also employed to detect changes in vegetation such as in plantation area, high vegetation area and dry agricultural area. In the Hindu Kush Himalaya, NDVI is utilized to detect changes in vegetation area by distinguishing the vegetation pixels from non-vegetation pixels (Anderson, 2020).

After NDVI, MODIS emerged as the third most used keyword, which is as expected because MODIS has an NDVI product called MOD13Q1 v006, which is generated every 16 days at a spatial resolution of $250 \mathrm{~m}(\mathrm{~m})$ and is classified as a Level 3 product (LP DAAC 2021). The product service has been servicing the global community since before 2010. Naturally, MODIS product ranking improved as the NDVI increased. However, the frequency appearance of "NDVI" fluctuated throughout 2014 to 2017 and then increased until 2019. Simultaneously, the red-edge band began to appear in vegetation health indices research in 2015 and 2016, which revealed its use in distinguishing between poor and good vegetative health (Imanishi et al., 2004; Wang et al., 2016; Zhang \& Zhou, 2015). As a 
result, the NDVI is less used in studies where the red-edge index was first used, particularly for agricultural purposes.

Another reason to attribute the fluctuation is the use of other vegetation indices, such as the Leaf Area Index (LAI) for estimating green biomass (Heenkenda et al., 2016; Tan et al., 2014; Wu, 2014; Zhang \& Zhou 2015). Meanwhile, other indices such as the Enhanced Vegetation Index (EVI) and Normalized Difference Water Index (NDWI) were associated with data on climate variables (Ladle et al., 2010). The trends from 2016 to 2020 showed that NDVI and other vegetation indices have become essential quantitative instruments in remote sensing, and the NDVI keyword will become more widely recognized as an active instrument in vegetation studies.

\subsection{Landsat and moderate resolution imaging spectroradiometer (MODIS)}

"Landsat" and "MODIS" refer to satellite data and sensors, respectively. As time passes, the resolution of satellite data changes and users now have the option of analysing between low- and high-resolution satellite data. Many providers even offer users high-resolution satellite data. Regardless, given the ease of accessibility and data acquisition, high-resolution satellite data are preferable for better analysis and understanding. In the most common author keywords, "Landsat" and "MODIS" appeared in the opposite order.

During the study period, MODIS was retained as the top five author keywords, while Landsat ranked eighth, indicating the capability of MODIS and its usage in remote sensing research. MODIS has three spatial resolutions of $250 \mathrm{~m}, 500 \mathrm{~m}$, and $1000 \mathrm{~m}$, as well as one to two days of temporal resolution, making it ideal for most worldwide application studies even after ten years. Numerous research has used MODIS as a worldwide overview of vegetation state since the application demonstrated an increase in demand from 2010 to 2020 , whereas the demand for Landsat has decreased.

Landsat is one of the first satellite data and sensors during the introduction of remote sensing. Landsat data are now publicly accessible from the US Geological Survey (USGS) on the EarthExplorer website, which enables us to explore and examine with satellite data more precisely. Over the years, Landsat has demonstrated its capabilities to compete with other satellite data owing to its open-source feature. Much research has been undertaken for temporal historical land use change. However, the emergence of other satellites, such as WorldView, SPOT 8, GeoEye, and others, which provide greater resolution, has put Landsat in a disadvantage position; hence, the rapid decline observed during the study period, from 36 in 2010 to 9 in 2020 . Nonetheless, Landsat data are still utilized for various research in 2020.

The growth pattern of the keywords "MODIS" and "Landsat" indicates that both remain essential over the next five years. Landsat satellite data time series, for example, were used to observe aquatic vegetation in a shallow lake in China, also known as a yellow algal bloom (Qing et al., 2020). Similarly, in Vietnam, Landsat time-series data were also employed to study the influence of urban heat islands on ground surface temperature throughout the summer (Nguyen, 2020). This highlights the satellite's capability to assist with vegetation and land research in recent years.

Since 2020, the world has been facing an unprecedented situation caused by the COVID19 pandemic. According to the World Health Organization, the issue is expected to become the forefront of every aspect of life in the next five years (WHO, 2021). Nevertheless, the organization body remains committed to the quest for global solution in critical areas such as crop drought, forest fires, agricultural water stress, land use change, and urbanization. 
However, with many countries urging the focus of investigations to be pivoted to the pandemic's impact on the nations and the studies on vaccination and public health because of the health crises, financial resources for research in forests and plants are drying up.

Recently, researchers have used "remote sensing" to derive satellite data into spatial data, along with the Geographical Information System or "GIS". Remote sensing and GIS, in its essence, must work together with remote sensing producing satellite data, while the GIS analyses the data using specific spatial software. In terms of ranking, GIS experienced a slight decline during the study period, from the third in 2010 down to the sixth in 2020. With a total of 36 posts, the largest number of documents published with "GIS" was found in 2019. In the beginning, the study reveals that researchers chose to employ remote sensing rather than GIS to characterize their analyses. However, upon observing the current trends of open-source software, various software such as QGIS and GRASS GIS are offering applications and tools that combined GIS with pre-processing features. Catalyst Professional (PCI Geomatica), Erdas Imagine, and ENVI are licenced software that integrates both applications. ArcGIS, on the other hand, offers a built-in tool for image processing, which makes the GIS keyword hidden in remote sensing.

Climate change is a global occurrence in which the weather changes. It has been a hot topic for debate over the past decade as it had a major impact on the world. The rank of climate change rose significantly from $23^{\text {rd }}$ in 2010 to eighth in 2020, indicating the primary focus in much research. It also suggests its prominence as a research hotspot in the future. Between 2010 and 2011, a total of 195 papers were published with the keyword climate change. It is a typical independent variable or parameter in remote sensing study. In the Southeast Asian region, for example, Liew et al., (2011) presented a report on climate change using remotely sensed knowledge. This is because remote sensing is a valid input whose data are available online and publicly accessible at no cost from open-source websites. Massive temporal analyses are also available using open-source data, and by utilising remote sensing, the effects of climate change can be observed in many geographical locations, temporal and spatial resolution. Elsewhere, Pauca-Tanco (2012) uses Landsat timeseries data to track and analyse climate change in wetland vegetation in Peru.

\subsection{Policy impacts on mangrove land use change using remote sensing/GIS}

In this study, documents relevant to the policy have been collected from the total publications listed above. One of them is a report on countries' developing policies, which is preceded by Hou et al., (2016). The study evaluated policy on substituting farmland for forests and its effect on land use and ecological vulnerability in Yan'an, China. In another study on remote sensing of mangrove land use, Wang et al. (2020) categorized the vulnerability of the ecology into potential, slight, medium, and heavy to assists China's Environmental Protection Law. Wongsai (2012), on the other hand, studied the changes in land use in Phuket for urban planning policy and found that the buildings were being built on land that should be used for farmland and nature reserves. The study reported the rate of transformation from forest conservation and rural and agricultural areas to residential areas by $3.19 \%$ $\left(10.051 \mathrm{~km}^{2}\right)$ and $10.95 \%\left(15.598 \mathrm{~km}^{2}\right)$, respectively, after observation through Phuket Town Planning Policy in 2005 and 2009. Mu et al. (2012) used remote sensing to track changes in Central China's landscape patterns and concluded that agricultural preservation policies should be weighted as before since the population has continued to increase, which results in rapid urban development. Therefore, further studies on land use change policies should be carried out and derive the proposal based on the outcomes. 


\subsubsection{Sustainable development goal (SDG)}

In terms of policy, the United Nations has rightly established the Sustainable Development Goals (SDGs) in conjunction with the declaration of "A blueprint to achieve a better and more sustainable future for all by 2030" (United Nation 2019). Unfortunately, the COVID-19 outbreak has disrupted the implementation of the SDG in 2020, causing it to fall short of the target (The Sustainable Development Goals 2020).

In 2015, 195 nations joined forces with the United Nation pledging to make the world a better place (Wang et al., 2019a, b). The SDG goals contain a list of research areas that scientists can focus on. Please visits United Nation website (https://sdgs.un. org/goals) to get more information about the goals. The SDG goals will ensure that the land will be saved, as shown by the promising outcomes from articles and conference papers produced for mangrove land use change using remote sensing, especially in tropical countries. This study topic falls on Life on Land of SDG 15, which concerns the protection, restoration, and promotion of sustainable use of terrestrial ecosystems, sustainable forests management, combat desertification, halt and reverse land degradation and halt biodiversity loss. If the outcomes continuously produce a performance over the next five years, this agenda will eventually be achieved. The study anticipates that the remote sensing keyword will continue to reign while the climate change keyword will rise in mangrove land use topics in the future.

Specifically, the keywords "land use" and "land use change" are associated very much with the SDG in many regards, i.e. SDG 6, SDG 11, SDG 13, and SDG 15. Changes in the pattern of keywords from land use to land use change showed that researchers are aware of the importance of safeguarding life on land through remote sensing tools. The study also urged more research in the future to use NDVI and other vegetation indices that deal with mangrove land use and land use change issues in tropical countries. Based on the findings, the use of NDVI, vegetation index, and vegetation indices from 2010 to 2020 show potential with increasing usage in this research topic.

Good forest management on using the land for urbanization and proper utilization of forest resources may save human's existence on earth. Forest monitoring efforts support SDG 13 (Climate Action) and SDG 14 (Life Below Water) (The Sustainable Development Goals 2020), which are related to the use of MODIS and Landsat keywords. These satellites enable the SDG to be realized within a reasonable period through a wide range of satellite products and open-source capabilities. The number of publications using satellite images for mangrove land use change is increasing. Thus, this study also anticipates more research into the use of open-source Landsat data and new products offered by MODIS for tackling and monitoring the mangrove depletion issue. These two satellites are projected to play a crucial role in assessing land use change in forested areas, with significant potential of the satellite to be used in other regions indefinitely as seen by their increased utilization.

The goals of the SDGs allow greater emphasis on research funding at the international and local levels. Likewise, between reach and focal issues, universities and academic organizations should operate within the SDG objectives. Therefore, the SDG should aim to provide feedback on scientific information published in journal articles, conference papers, and reports on the application of remote sensing technology. Coordination for better information transmission to policymakers is also essential for successful resource management policy. 


\subsubsection{Policy impact on food security}

Food security is a complex issue that is being discussed across sectors in academia. It is affected primarily by agricultural activities, especially when there is a shortage and drought occurrence, which in turn, pose threats to climate change. Research on land use change in mangrove areas provides precautionary measures against the perils to food safety. The increased use of technology has sped up conservation efforts of high-risk mangroves from future degradation. For example, despite the maintenance, preservation, and harvest management efforts in the Matang Mangrove Forest Reserve in the Malaysian Peninsula (Goessens et al., 2014), the mangrove system remains vulnerable to potential degradation if remote sensing technology is not used soon enough. Generally, food security involves ensuring an adequate supply of food and its access by the population, mostly through generating sufficient demand via income growth or transfers. That is, encouraging the farmers and industrial player into adopting technology that can efficiently monitor plant growth in agricultural fields.

Because vegetation indices, particularly NDVI, can measure plant status, it has become a desirable technique in measuring plant health and vigour. The NDVI from leaf level can be measured using Green Seeker instruments, which is then digitally converted for spatial interpolation and further analysis. The NDVI from canopy level is a normalized ratio of near-infrared to visible red that can be retrieved from satellite images (Rouse et al., 1974). Throughout the assessment period from 2010 to 2020, NDVI has become an essential tool in measuring the mangrove, which utilized MODIS or Landsat satellite image. Both NDVI and MODIS showed significant progress, indicating their availability for use in other important forest landscape change studies. Thus, food production can be increased and stabilized through remote sensing and GIS techniques. Also, the study recommends government intervention to strengthen a country's food security policy.

In a study, the ability of NDVI and other vegetation indices to discriminate between healthy and infected palms was evaluated. Chong et al., (2017) have found the sign of low vital that indicates a symptom of Ganoderma disease. Malaysia, Indonesia, Thailand, and Papua New Guinea together produced nearly $90 \%$ of the world's palm oil output in $2000(\mathrm{Ng}, 2000)$. Since then, palm oil has made a massive contribution to the national income, benefitting 570,000 people in Malaysia alone, with another 290,000 people employed downstream. Therefore, the study showed that, in addition to NDVI, other indices also serve a similar role in strengthening food security in the context of mangrove land use change. Regardless, the frequency of keyword appearance for NDVI remains higher than any other indices, based on the 10 top-keywords finding. It also indicates that NDVI is highly used in mangrove land use change analysis since 2010 with increased frequency of usage. Other than the NDVI, a highly responsive index to land use change should be tested in tropical countries since it was generated more than 30 years ago (Rouse et al., 1974). Other indexes such as red-edge that utilized red-edge wavelength as discussed in the previous section can be a supporting tool for speedy detection of changes in mangrove that are due to degradation and assists food security policy development. This is because the index can detect disease in the agricultural area as tested in oil palm plantation and recently in a forested area.

Food security in developing countries tends to be influenced by both micro- and macro-factors such as the adoption of new technologies, support for farmer-accessible institutions, food price policy, as well as monetary, fiscal, and exchange rate policies 
that affect the overall economic growth and income distribution. Such issues are elaborately discussed in a book entitled "Food Security Policy in Developing Countries" by Abdulai and Kuhlgatz, (2012). The food security agenda is categorized under SDG No. 2 , based on ending hunger, achieve food security and improved nutrition, and promote sustainable agriculture.

In 2018, a food security report has recommended innovative technology in precision farming systems that could be game-changers to the future of food security systems (Stordalen \& Fan, 2018). The top keywords most used by researchers in mangrove land use change studies indicate the extensive use of remote sensing tools between 2010 and 2020, as shown by the predominant appearance of "remote sensing" keyword in articles and conference research. Hence, the study can help future research to respond readily to the various needs in the future in developing effective policy for food security.

The COVID-19 pandemic, which has brought the globe to a standstill, has caused multiple meltdowns with devastating impacts on food systems, social, and economic development (Swinnen \& McDermott, 2020). However, agricultural sectors are emerging stronger as a result of increased awareness of technology-wise management such as precision farming that uses automated fertilizer and irrigation management. The application of remote sensing of indices, which are currently published in various documents category, creates a possibility for a larger company to explore. Also, it facilitates pest and disease assessment, monitoring of drought conditions, regulate the use of fertilisers and estimation of crop growth productivity. Presumably, relevant organizations and policymakers may have overlooked scientific information that is documented in different format, i.e. journal articles, short communication, and reports, in favour of simple publications designed for the layman.

\subsubsection{Policy impact on forest resources}

The publication mentioned and discussed above further illustrated the present situation on the ground in which some of the research is conducted based on current trends of issues. This was emphasized by Kanniah et al. (2015), where mangroves were converted to land use activities from 1989 to 2014, including residential areas, oil palm plantations, wetlands, barren land and industrial land as the government undertook economic ventures. The research focused on this subject gives a huge impact to policymaker in governing forest resources, which the finding identified the significance of remote sensing in monitoring palm oil, particularly that concerns industrial, environmental, and economic aspects.

This is because natural regeneration ensures long-lasting flora and fauna and the presence of forest species of similar quality in the future. It can also be an important source of recovery of ecosystem services (ES), which is critical for humanity, especially for climate change mitigation and adaptation goals (Naime et al. 2020). Among the various types of documents collected for this study, the report on countries' developing policies preceded by Hou et al., (2015) is noteworthy. It pertains to policy evaluation of substituting farmland from forests and its effect on land use and ecological vulnerability in Yan'an, China. In another study, Boupun and Wongsai (2012) examined the changes in land use in Phuket for urban planning policy and found that the buildings were built on land that should be used for farmland and nature reserves. Mu et al. (2012) used remote sensing to track changes in Central China's landscape patterns and concluded that agricultural preservation policies should be weighted as before, since the population continues to increase which results in 
rapid urban development. Therefore, further studies on policy-related land use change are necessary to derive a recommendation.

Malaysia has taken a step forward to become a party to the Convention on Biological Diversity in 1992 and the National Biodiversity Committee that was set up in 1994, along with neighbouring countries such as Thailand, Vietnam, Laos and Indonesia; they have at least one mangrove identified that was adopted to this convention. The statement that links to mangrove land use change using remote sensing tools is where many publications analysed in this study support the RAMSAR agenda, specifically with the usage of MODIS and Landsat for the protection of mangrove area. The objective of the RAMSAR agenda is to protect and manage international biological resources and ensure the fair and equitable sharing of biological resources and technology. Since RAMSAR requires additional studies in assessing the status of mangrove in tropical countries, the present study aptly supports the agenda of RAMSAR.

\section{Conclusion}

The studies on mangrove land use change in tropical countries using remote sensing/GIS have been investigated from two different perspectives, notably the forestry and agricultural as well as policy impact on food security and forest resources. The study's goal was to assess the scientific information on changes in land use of tropical mangrove forests based on remote sensing. The study specifically explored patterns in the incidence of land use change via the evolution of publications.

This study concludes that mangrove land use change studies have evolved from using NDVI from Landsat data to using updated products of MODIS to detect changes in vegetation for better understanding and classification of the land use change of the area. This study found, the use of spatial tools, such as remote sensing and GIS in drought studies, can be identified as one of fundamental research methodologies that has yet to be fully explored, especially in the use of vegetation indices. Therefore, there is a need to focus on the use of these tools for future research endeavours given the advantage offered by the technologies. The present study also determines that the use of NDVI and other vegetation indices that can be used for example Enhanced Vegetation Index (EVI) is an emerging subject for mangrove land use change. Therefore, the study proposed the use of these technologies is coupled with machine learning as a means to provide rapid and adequate tools needed for the development of integrated mangrove land use techniques. Specifically, for the purpose of updating status on tropical mangrove detection in which the tools could facilitate scaling to regional and local scales. Most importantly, the usability of vegetation indices using a different scale and resolution are identified as the major future research gap that has to be addressed.

Continuous research revealed that nagging issues occurring in tropical countries could affect policy implementation in terms of safeguarding food and forest resources. The agenda established in the SDG is comprehensive, which includes addressing the issues on forest resources, food security, humanity and most importantly, climate change. With solid support from countries across the globe, the research gaps can be resolved through research undertakings financed by multiple organizations with strong interests in the subject such as universities, institutions, and companies.

The study also discovered that some of the techniques of mangrove detection on assessing land use change are already implemented but are kept confidential, or its publication 
may not be intended for scholarly use. Therefore, it could present a valuable research gap that has to be addressed in the future. Regardless, other forms of communication such as seminar, webinars, and short talks by industries and companies can be one of the methods to assemble the information and techniques that are known only to the industries. This article demonstrated that there are many mangrove forests that need to be saved as soon as feasible. Similar challenges occur around the world, such as forest depletion.

There are several limits to the study, such as the fact that it can only be conducted using a database subscribed to by your university. This entailed a higher subscription fee, which should be maintained. However, there are additional solutions, such as using freeware to acquire literature databases that are not covered in this work. Currently available tools for research application are costly such as the land use change system integrated with various satellite images and product inclusion of land uses. As a result, more donors should donate to this type of study to protect more mangrove forests for future generations. Simultaneously, research in collaboration with global organizations should be prioritized to ensure that the study objective can be implemented in other parts of the world. Therefore, future research could benefit from the fruitful cooperation of various organization such as the Food and Agricultural Organization (FAO) and local agencies of the agricultural aspect.

\section{References}

Abdulai, A., \& Kuhlgatz, C. (2012). Food Security Policy in Developing Countries. The Oxford Handbook of the Economics of Food Consumption and Policy. https://doi.org/10.1093/oxfordhb/9780199569441. 013.0014

Adisa, O. M., Masinde, M., Botai, J. O., \& Botai, C. M. (2020). Bibliometric analysis of methods and tools for drought monitoring and prediction in Africa. Sustainability., 12(16), 6516. https://doi.org/10.3390/ su12166516

Alon, A. S., Festijo, E. D., \& Casuat, C. D. (2020). Tree extraction of airborne lidar data based on coordinates of deep learning object detection from orthophoto over complex mangrove forest. International Journal of Emerging Trends in Engineering Research., 8, 2107-2111. https://doi.org/10.30534/ijeter/ 2020/103852020

Althuwaynee, O. F., Pradhan, B., \& Lee, S. (2012). Application of an evidential belief function model in landslide susceptibility mapping. Computers and Geosciences, 44, 120-135. https://doi.org/10.1016/j. cageo.2012.03.003

Amoakoh, A. O., Aplin, P., Awuah, K. T., Delgado-fernandez, I., Moses, C., Alonso, C. P., et al. (2021). Testing the contribution of multi-source remote sensing features for random forest classification of the greater amanzule tropical peatland. Sensors, 21(10), 3399. https://doi.org/10.3390/s21103399

Anderson, K., Fawcett, D., Jones, D., Leng, R., Anderson, K., \& Fawcett, D. (2020). Vegetation expansion in the subnival hindu Kush Himalaya (August2019). Global Change Biology., 26(3), 1608-1625. https://doi.org/10.1111/gcb.14919

Bhd, A. S., Camay, B., Putih, J. P. (2000). Nutrition and Nutrient Management of the Oil Palm - New Thrust for the Future Perspective, 415-429.

Bindu, G., Rajan, P., Jishnu, E. S., \& Ajith Joseph, K. (2020). Carbon stock assessment of mangroves using remote sensing and geographic information system. Egyptian Journal of Remote Sensing and Space Science, 23(1), 1-9. https://doi.org/10.1016/j.ejrs.2018.04.006

Boupun, P., Wongsai, S. (2012). Land use change and the town planning policy of Phuket. 33rd Asian Conference on Remote Sensing 2012, ACRS 2012, 1(January 2012), 278-281.

Cardoso-Fernandes, J., Teodoro, A. C., \& Lima, A. (2019). Remote sensing data in lithium (Li) exploration: a new approach for the detection of Li-bearing pegmatites. International Journal of Applied Earth Observation and Geoinformation., 76, 10-25. https://doi.org/10.1016/j.jag.2018.11.001

Chong, K. L., Kanniah, K. D., Pohl, C., \& Tan, K. P. (2017). A review of remote sensing applications for oil palm studies. Geo-Spatial Information Science, 20(2), 184-200. https://doi.org/10.1080/10095020. 2017.1337317 
Cissell, J. R., Delgado, A. M., Sweetman, B. M., \& Steinberg, M. K. (2018). Monitoring mangrove forest dynamics in Campeche, Mexico, using landsat satellite data. Remote Sensing Applications: Society and Environment, 9, 60-68. https://doi.org/10.1016/j.rsase.2017.12.001

De-miguel-molina, B., Albors, J. (2015). How undertake a literature review through Bibliometrics. An example with review about " user innovation" How undertake a literature review through bibliometrics . An example with review about user innovation. https://doi.org/10.4995/ICBM.2015.1327

The sustainable development goals. (2020). The Sustainable Development Goals Report.

Diniz, C., Cortinhas, L., Nerino, G., Rodrigues, J., Sadeck, L., Adami, M., \& Souza-Filho, P. W. M. (2019). Brazilian mangrove status: three decades of satellite data analysis. Remote Sensing, 11(7), 808. https:// doi.org/10.3390/rs11070808

Dorjsuren, M., Liou, Y. A., \& Cheng, C. H. (2016). Time series MODIS and in situ data analysis for Mongolia drought. Remote Sensing, 8(6), 1-16. https://doi.org/10.3390/rs8060509

Duan, P., Wang, Y., \& Yin, P. (2020). Remote sensing applications in monitoring of protected areas. A Bibliometric Analysis., 12(5), 772.

Giri, C., Ochieng, E., Tieszen, L. L., Zhu, Z., Singh, A., Loveland, T., \& Duke, N. (2011). Status and distribution of mangrove forests of the world using earth observation satellite data. Global Ecology and Biogeography, 20(1), 154-159. https://doi.org/10.1111/j.1466-8238.2010.00584.x

Goessens, A., Satyanarayana, B., Van Der Stocken, T., Zuniga, M. Q., Mohd-Lokman, H., Sulong, I., \& Dahdouh-Guebas, F. (2014). Is Matang Mangrove Forest in Malaysia sustainably rejuvenating after more than a century of conservation and harvesting management? PLOS ONE, 9(8). https://doi.org/10. 1371/journal.pone.0105069.

Hou, K., Li, X., \& Wag jingZhang, J. J. (2016). An analysis of the impact on land use and ecological vulnerability of the policy of returning farmland to forest in Yan'an. China. Environmental Science and Pollution Research, 23(5), 4670-4680. https://doi.org/10.1007/s11356-015-5679-9

Huang, Q., \& Lu, Y. (2017). Urban heat island research from 1991 to 2015 a bibliometric analysis. Theoretical and Applied Climatology., 131(3-4), 1055-1067. https://doi.org/10.1007/s00704-016-2025-1

Jia, M., Wang, Z., Zhang, Y., Mao, D., \& Wang, C. (2018). Int J Appl Earth Obs Geoinformation Monitoring loss and recovery of mangrove forests during 42 years : the achievements of mangrove conservation in China. Int J Appl Earth Obs Geoinformation, 73(July), 535-545. https://doi.org/10.1016/j.jag. 2018.07.025

Jiyuan, L. I. U., Wenhui, K., Zengxiang, Z., \& Xinliang, X. U. (2014). Spatiotemporal characteristics, patterns, and causes of land use changes in China since the late. Journal of Geographical Sciences., 24(2), 95-210. https://doi.org/10.1007/s11442-014-1082-6

Kanniah, K. D., Sheikhi, A., Cracknell, A. P., Goh, H. C., Tan, K. P., Ho, C. S., \& Rasli, F. N. (2015). Satellite images for monitoring mangrove cover changes in a fast growing economic region in southern Peninsular Malaysia. Remote Sensing, 7(11), 14360-14385. https://doi.org/10.3390/rs71114360

Kuenzer, C., Gebhardt, S., \& Vo, T. Q. (2011). Remote Sensing of Mangrove Ecosystems : a Review. https:// doi.org/10.3390/rs3050878

Ladle, R., Arai, E., Barbier, N., Anderson, L. O., Malhi, Y., Araga, L. E. O. C., \& Anderson, L. O. (2010). Remote sensing detection of droughts in Amazonian forest canopies. New Phytologist., 187, 733-750.

Liew, S. C., Chia, A. S., Kwoh, L. K. (2011). Spatio-temporal analysis of climate change parameters using satellite data for the southeast Asian region. 34th International Symposium on Remote Sensing of Environment - The GEOSS Era: Towards Operational Environmental Monitoring, (1), 1-4.

Liou, Y. A., Sha, H. C., Chen, T. M., Wang, T. S., Li, Y. T., Lai, Y. C., \& Lu, L. T. (2012). Assessment of disaster losses in rice paddy field and yield after tsunami induced by the 2011 great east Japan earthquake. Journal of Marine Science and Technology (taiwan), 20(6), 618-623. https://doi.org/10.6119/ JMST-012-0328-2

Lopes, M. S., \& Reynolds, M. P. (2012). Stay-green in spring wheat can be determined by spectral reflectance measurements (normalized difference vegetation index) independently from phenology. Journal of Experimental Botany, 63(10), 3789-3798.

Mao, Z., Chen, J., Hao, Z., Pan, D., Tao, B., \& Zhu, Q. (2013). A new approach to estimate the aerosol scattering ratios for the atmospheric correction of satellite remote sensing data in coastal regions. Remote Sensing of Environment, 132, 186-194. https://doi.org/10.1016/j.rse.2013.01.015

Mu, B., Mayer, A. L., He, R., \& Tian, G. (2016). Land use dynamics and policy implications in Central China: a case study of Zhengzhou. Cities, 58, 39-49. https://doi.org/10.1016/j.cities.2016.05.012

Muhuri, P. K., Shukla, A. K., \& Abraham, A. (2019). Engineering Applications of Artificial Intelligence Industry 4 0: A bibliometric analysis and detailed overview. Engineering Applications of Artificial Intelligence, 78, 218-235. https://doi.org/10.1016/j.engappai.2018.11.007

Müller, A. M., Ansari, P., Ebrahim, N. A., \& Khoo, S. (2016). Physical activity and aging research: a bibliometric analysis. Journal of Aging and Physical Activity., 24, 476-483. 
Naime, J., Mora, F., Sánchez-martínez, M., Arreola, F., \& Balvanera, P. (2020). Forest Ecology and Management Economic valuation of ecosystem services from secondary tropical forests : trade-o ff $\mathrm{s}$ and implications for policy making. Forest Ecology and Management, 473, 118294. https://doi.org/10. 1016/j.foreco.2020.118294

Nguyen, T. T. (2020). Landsat time-series images based urban heat island analysis: The effects of changes in vegetation and built-up land on land surface temperature in summer in the hanoi metropolitan area, Vietnam. Environment and Natural Resources Journal. 18 177-190. https://doi.org/10. 32526/ennrj.18.2.2020.17

Olorunfemi, I. E., Komolafe, A. A., Fasinmirin, J. T., Olufayo, A. A., \& Akande, S. O. (2020). A GISbased assessment of the potential soil erosion and flood hazard zones in Ekiti State, Southwestern Nigeria using integrated RUSLE and HAND models. CATENA, 194, 104725. https://doi.org/10. 1016/j.catena.2020.104725

Oostdijk, M., Santos, M. J., Whigham, D., Verhoeven, J., \& Silvestri, S. (2018). Estuarine, Coastal and Shelf Science Assessing rehabilitation of managed mangrove ecosystems using high resolution remote sensing. Estuarine, Coastal and Shelf Science, 211, 238-247. https://doi.org/10.1016/j.ecss. 2018.06.020

Panuju, D. R., Paull, D. J., \& Gri, A. L. (2020). Change Detection Techniques Based on Multispectral Images for Investigating Land Cover. Dynamics, 12(11), 1781.

Pastor-Guzman, J., Dash, J., \& Atkinson, P. M. (2018). Remote sensing of mangrove forest phenology and its environmental drivers. Remote Sensing of Environment, 205, 71-84. https://doi.org/10. 1016/j.rse.2017.11.009

Pauca-Tanco, A., Ramos-Mamani, C., Luque-Fernández, C. R., Talavera-Delgado, C., Villasante-Benavides, J. F., Quispe-Turpo, J. P., \& Villegas-Paredes, L. (2020). Spatio temporal and climatic analysis of the high andean wetland of chalhuanca (Peru) during the period 1986-2016. Revista De Teledeteccion, 2020(55), 105-118. https://doi.org/10.4995/raet.2020.13325

Pham, L. T. H., Vo, T. Q., Dang, T. D., \& Nguyen, U. T. N. (2019). Monitoring mangrove association changes in the Can Gio biosphere reserve and implications for management. Remote Sensing Applications: Society and Environment, 13(18), 298-305. https://doi.org/10.1016/j.rsase.2018.11.009

Qing, S., Shun, B., Zhao, W., Bao, Y., \& Hao, Y. (2020). Distinguishing and mapping of aquatic vegetations and yellow algae bloom with Landsat satellite data in a complex shallow Lake China during 1986-2018. Ecological Indicators., 112, 106073. https://doi.org/10.1016/j.ecolind.2020.106073

Ramsar. (2016). An Introduction to the Ramsar Convention on Wetlands (7th ed.). Ramsar Convention Secretariat, Gland, Switzerland. www.facebook.com/RamsarConventionOnWetlands\%0AInstagram

Rochdane, S., Bounoua, L., Zhang, P., Imhoff, M., Messouli, M., \& Yacoubi-Khebiza, M. (2014). Combining satellite data and models to assess vulnerability to climate change and its impact on food security in morocco. Sustainability, 6, 1729-1746. https://doi.org/10.3390/su6041729

Rouse, J. W., Haas, R. H., Schell, J. A., \& Deering, D. W. (1974). Monitoring vegetation systems in the Great Plains with ERTS. In: Proceedings of the Third Earth Resource Technology Satellite-1 Symposium. 3010- 3017. Washington, United States NASA.

Rudorff, B. F. T., de Aguiar, D. A., da Silva, W. F., Sugawara, L. M., Adami, M., \& Moreira, M. A. (2010). Studies on the rapid expansion of sugarcane for ethanol production in São Paulo state (Brazil) using Landsat data. Remote Sensing, 2(4), 1057-1076. https://doi.org/10.3390/rs2041057

Sharma, C. S., Behera, M. D., Mishra, A., \& Panda, S. N. (2011). Assessing flood induced land-cover changes using remote sensing and fuzzy approach in Eastern Gujarat (India). Water Resources Management, 25(13), 3219-3246. https://doi.org/10.1007/s11269-011-9853-7

Shihua, L., Jiangtao, X., Ping, N., Jing, Z., \& Hongshu, W. (2014). Monitoring paddy rice phenology using time series modis data over Jiangxi province, China. International Journal of Agricultural and Biological Engineering, 7(6), 28-36. https://doi.org/10.3965/j.ijabe.20140706.005

Shiva Shankar, V., Dharanirajan, K., Agarwal, D. K., Manoharan, N., \& R. M., \& Rajmohan, K. (2013). Pre and post tsunami changes of land use and land cover in the little Andaman Island, India: a Geospatial approach. International Journal of Earth Sciences and Engineering, 6(1), 80-86.

Staben, G., Lucieer, A., \& Scarth, P. (2018). Modelling LiDAR derived tree canopy height from Landsat TM, ETM+ and OLI satellite imagery-a machine learning approach. International Journal of Applied Earth Observation and Geoinformation, 73(April), 666-681. https://doi.org/10.1016/j.jag. 2018.08.013

Stordalen, G., Fan, S. (2018). The Global Food System under Radical Change. Washington, United States. https://www.ifpri.org.

Swinnen, J., McDermott, J. (2020). COVID-19: Assessing impacts and policy responses for food and nutrition security. COVID-19 and global food security. https://doi.org/10.2499/p15738coll2.133762_01 
United Nation. (2019). The global movement for our children's future- world top 20 project. United Nation. www.worldtop20.org. Accessed 21 October 2020

Vijaylakshmi, S. (2013). Remote Sensing Literature in Scopus Database : A Bibliometric Analysis, 3(1), $70-86$.

Wang, L., Jia, M., Yin, D., \& Tian, J. (2019a). A review of remote sensing for mangrove forests. Remote Sensing of Environment, 231, 1111223. https://doi.org/10.1016/j.rse.2019.111223

Wang, L., Zhang, G., Wang, Z., Liu, J., Shang, J., \& Liang, L. (2019b). Bibliometric Analysis of Remote Sensing Research Trend in Crop Growth Monitoring :A Case Study in China. https://doi.org/10.3390/ rs11070809

Yin, J., Yin, Z., Zhong, H., Xu, S., Hu, X., Wang, J., \& Wu, J. (2011). Monitoring urban expansion and land use/land cover changes of Shanghai metropolitan area during the transitional economy (1979-2009) in China. Environmental Monitoring and Assessment, 177(1-4), 609-621. https://doi.org/10.1007/ s10661-010-1660-8

Yu, D., Xu, Z., \& Wang, X. (2019). Bibliometric analysis of support vector machines research trend: a case study in China. International Journal of Machine Learning and Cybernetics., 11(715), 728. https://doi. org/10.1007/s13042-019-01028-y

Yu, W., Zhou, W., Qian, Y., \& Yan, J. (2016). A new approach for land cover classification and change analysis: Integrating backdating and an object-based method. Remote Sensing of Environment, 177, 37-47. https://doi.org/10.1016/j.rse.2016.02.030

Zabolotskikh, E. V., Mitnik, L. M., \& Chapron, B. (2013). New approach for severe marine weather study using satellite passive microwave sensing. Geophysical Research Letters, 40(13), 3347-3350. https:// doi.org/10.1002/grl.50664

Zhang, H., Huang, M., Qing, X., Li, G., \& Tian, C. (2017). Bibliometric analysis of global remote sensing research during. ISPRS International Journal of Geo-Information., 6(11), 332. https://doi.org/10.3390/ ijgi6110332

Zhuang, Y., Liu, X., \& Nguyen, T. (2013). Global remote sensing research trends during 1991-2010: a bibliometric analysis. Scientometrics., 96, 203-219. https://doi.org/10.1007/s11192-012-0918-z

Publisher's Note Springer Nature remains neutral with regard to jurisdictional claims in published maps and institutional affiliations.

\section{Authors and Affiliations}

\section{Sheriza Mohd Razali ${ }^{1}$ (D) Maizatul Azwa Radzi ${ }^{1} \cdot$ Arnaldo Marin $^{2} \cdot$ Zaiton Samdin $^{1}$}

Maizatul Azwa Radzi

maizatulazwa96@gmail.com1

1 Institute of Tropical Forestry and Forest Products (INTROP), Universiti Putra Malaysia, UPM, 43400 Serdang, Selangor, Malaysia

2 Departamento de Ecología e Hidrología, Facultad de Biología, Universidad de Murcia, Campus de Espinardo, 30003 Murcia, Spain 